\title{
Corrigendum
}

\section{PLAY AND PLAYFULNESS: DEVELOPMENTAL, CULTURAL AND CLINICAL ASPECT}

edited by Monisha C. Akhtar, Jason Aronson, New York, 2011, 234pp.

\section{Book reviewed by Jeanne Bailey, M.D.}

DOI:10.1057/ajp.2013.34

Correction to: The American Journal of Psychoanalysis, (2012) 72, 421-424. doi: 10.1057/ajp.2012.23

The author's name for one of the sections of the book was mistakenly given as Davies.

The correct section is as follows:

In a lovely paper, Lucy Daniels describes her crippled voice beside a father who preferred her to be inadequate. Her award-winning first book exacerbated her anorexia as other writers have succumbed to symptomatic deflated selves when their writing pulled at unacknowledged and previously unmanaged feelings and conflicts. She agrees with Winnicott (1969) that one need not be too consciously scared or defended as a state of freeness for creativity. However, she prefers Ogden's elaboration of creativity arising from a necessary tension between differences: fantasy and reality, self and other; thought and feeling. Her reminder that necessity is the mother of invention is familiar to psychoanalysts when pain drives discovery. Daniels credits her analyst with providing a space to know herself through her dreams and utilize them to inform her struggles with inhibition of creativity. Again, we find safety beside the essential tension of disruption, difference and pain. 